\title{
Optimization of Material Removal Rate of WEDM Process on Mild Steel Using Molybdenum Wire
}

\author{
Harsh Saini, Irfan Khan, Sushil Kumar, Sahil Kumar
}

Department of Mechanical Engineering, Maharishi Ved Vyas Engineering College, Jagadhri, Haryana, India

\begin{abstract}
For any manufacturing process and, particularly, in process related to WEDM the correct selection of process parameters is one of the most important aspects to be taken into consideration. WEDM is capable of machining geometrically complex shapes or hard material components, such as composites, carbides, heat treated tool steels, super alloys, ceramics and heat resistant steels etc. These hard material components are widely used in die and mold making industries, aerospace, aeronautics and nuclear industries.

This study discusses the influence of process parameters like current, Pulse on time, Pulse off Time and Voltage on the performance parameters such as material removal rate. The experiment has been conducted on Mild Steel work piece using brass wire, because Mild Steel has various industrial applications in manufacturing of frame of motorcycles, dies, automobile chassis, base of boilers and cook wares etc. The experimental layout is based on Taguchi $L_{16}$ orthogonal array. Further, the analysis of variance [ANOVA] is used to analyze the results obtained from Taguchi method. The analysis of results obtained for material removal rate indicate that current and pulse on time has the highest impact on material removal rate. As the current and pulse on time increases, the material removal rate also increases. Pulse off time and voltage has no significant effect on material removal rate.
\end{abstract}

Keywords-Taguchi, ANOVA, WEDM, molybdenum, pulse on time, current, pulse off time.

\section{INTRODUCTION}

WEDM ever since its inception has shown a tremendous growth. The process of WEDM was computerized in 1974 and further in 1975 its features and capabilities were enhanced. Since WEDM involves various parameters which play an important role in the quality of the product so it became an area of interest for the researchers. The parameters which may affect the quality of the product are tool size; pulse in and off time, feed rate, current and voltage etc. A no. of papers has been published to study the effect of these parameters on the performance of the WEDM. Material removal rate was found to be increasing with increase in pulse on time and current whereas surface quality was affected [27]. Approximately $70 \%$ increase in productivity was reported by using coated electrode as compared to the uncoated electrode [24]. Various kind of design of experiment techniques such as full factorial design [19], Taguchi method [17, 20] and RSM [22] was also used to design the optimum number of experiments. Also WEDM was performed in different mediums and a medium having oxygen mist dielectric was suggested to be better. Going through the literature it was found that work related to ELCUT type wire cut machine tool along with the current, pulse on time, voltage and pulse off time as process parameters and material removal rate as response parameters is scare.

\section{EXPERIMENTS}

Due to the ease in availability and conductive nature a mild steel work piece having composition C $0.28 \%, \mathrm{Mn}$ $0.44 \%$, P $0.04 \%$ S $0.02 \%$ and Si $0.16 \%$ [wt \%] were selected as work piece. Molybdenum wire having 0.25 $\mathrm{mm}$ diameter was selected as electrode. ELCUT 234 machine [fig.1] Molybdenum wire having $0.25 \mathrm{~mm}$ diameter was selected as electrode. ELCUT 234 machine [fig.1] having 3- $\Phi$, AC $415 \mathrm{v}, 50 \mathrm{~Hz}$ was used to perform the experiments.

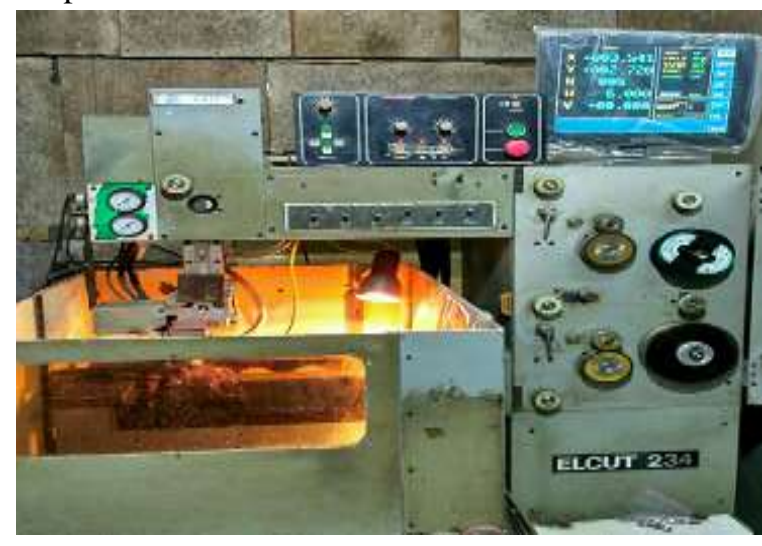

Fig.1: ELCUT 234 machine

An orthogonal array $\left[\mathrm{OA}_{16}\right]$ based on the Taguchi Design of experiments was selected based on the degree of freedom. Current, pulse on time, pulse off time and 
voltage were taken as process parameters and other parameters like wire feed rate, wire tension and flushing pressure were kept constant. De-ionized water was used as dielectric fluid to flush away the debris from the machining area.

Table.1: Observation Table

\begin{tabular}{|l|l|l|l|l|l|}
\hline Run & I & $\mathbf{T}_{\text {on }}$ & $\mathbf{T}_{\text {off }}$ & $\mathbf{V}$ & MRR \\
\hline 1 & 210 & 100 & 50 & 70 & 20.10 \\
\hline 2 & 210 & 105 & 55 & 75 & 21.41 \\
\hline 3 & 210 & 110 & 60 & 80 & 22.76 \\
\hline 4 & 210 & 115 & 65 & 85 & 23.59 \\
\hline 5 & 215 & 100 & 55 & 80 & 19.94 \\
\hline 6 & 215 & 105 & 50 & 85 & 22.83 \\
\hline 7 & 215 & 110 & 65 & 70 & 24.05 \\
\hline 8 & 215 & 115 & 60 & 75 & 24.97 \\
\hline 9 & 220 & 100 & 60 & 85 & 22.06 \\
\hline 10 & 220 & 105 & 65 & 80 & 24.36 \\
\hline 11 & 220 & 110 & 50 & 75 & 26.12 \\
\hline 12 & 220 & 115 & 55 & 70 & 27.18 \\
\hline 13 & 225 & 100 & 65 & 75 & 24.10 \\
\hline 14 & 225 & 105 & 60 & 70 & 27.04 \\
\hline 15 & 225 & 110 & 55 & 85 & 27.68 \\
\hline 16 & 225 & 115 & 50 & 80 & 28.83 \\
\hline
\end{tabular}

During the whole machining process a constant spark gap was be maintained with the help of servo mechanism system. The observed values of material removal rate for the experiment are shown in table 1.

The cut pieces of mild steel having $10 \mathrm{~mm} \times 5 \mathrm{~mm}$ in cross-section are shown in fig. 2:

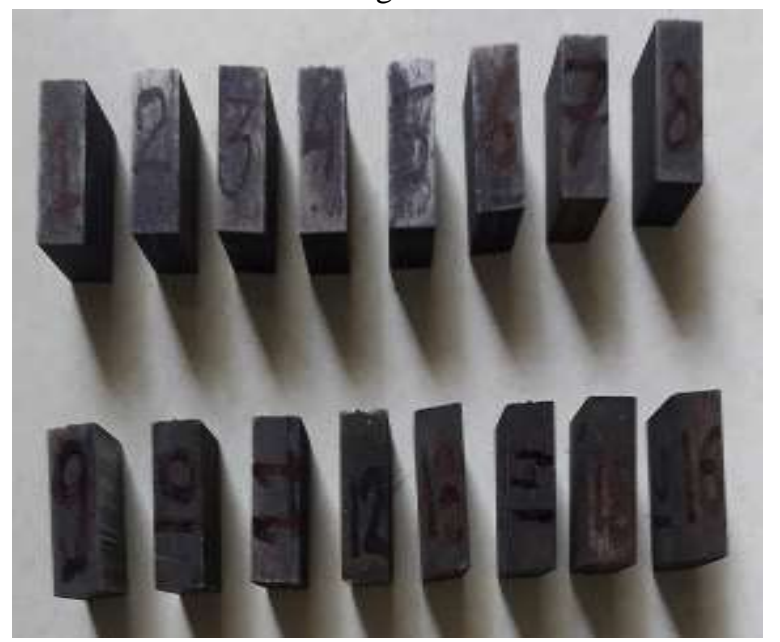

Fig.2: Cut Pieces of Mild Steel

\section{RESULTS AND DISCUSSION}

The $\mathrm{S} / \mathrm{N}$ ratio table along with process parameters is shown in table 2 whereas the response table for $\mathrm{S} / \mathrm{N}$ ratio is shown in table 3. The rank and delta values for Current, Pulse on Time, Pulse off Time and voltage 1, 2, 4 and 3 and delta $1.76,1.68,0.16$ and 0.24 respectively, in response table for $\mathrm{S} / \mathrm{N}$
Table.3: Response Table for S/N Ratio

\begin{tabular}{|c|c|c|c|c|}
\hline Level & I & Ton & Toff & V \\
\hline 1 & 26.82 & 26.64 & 27.69 & 27.75 \\
\hline 2 & 27.18 & 27.54 & 27.53 & 27.64 \\
\hline 3 & 27.91 & 27.99 & 27.65 & 27.52 \\
\hline 4 & 28.58 & 28.32 & 27.61 & 27.59 \\
\hline Delta & 1.76 & 1.68 & 0.16 & 0.24 \\
\hline Rank & 1 & 2 & 4 & 3 \\
\hline
\end{tabular}

Similarly, from response table for means shown in table 4.3 the rank and delta values for process parameters are1, 2,4 and 3 and 4.95, 4.59, 0.45 and 0.62 respectively any miscellaneous numbering system you use in your paper cannot be confused with a reference [4] or an equation (3) designation.

Table.4: Response Table for Means

\begin{tabular}{|c|c|c|c|c|}
\hline Level & I & Ton & Toff & V \\
\hline 1 & 21.97 & 21.55 & 24.47 & 24.59 \\
\hline 2 & 22.95 & 23.91 & 24.05 & 24.15 \\
\hline 3 & 24.93 & 25.15 & 24.21 & 23.97 \\
\hline 4 & 26.91 & 26.14 & 24.02 & 24.04 \\
\hline Delta & 4.95 & 4.59 & 0.45 & 0.62 \\
\hline Rank & 1 & 2 & 4 & 3 \\
\hline
\end{tabular}

The response table shows the relative importance of each process parameters towards the response. It is clears from these tables that the process parameter having greatest delta value gets highest rank. The rank indicates the relative significance of each process parameters to the response. Current gets rank 1 followed by pulse on time, voltage and pulse off time. So from the results based on delta value and rank it is conclude that current has the highest effect on material removal rate [MRR] followed by the pulse on time, voltage and lastly pulse off time.

\subsection{Regression Equation}

The regression equation for material removal rate as shown by equation [3.1] is calculated in MINITAB 17 software. The regression equation shows the significant effect of each process parameter on the material removal rate. From this equation, it is clears that the current and pulse on time have positively affect the material removal rate whereas pulse off time and voltage have negative effect on response i.e. material removal rate.

MRR $=-770.9+0.3365 \mathrm{I}+0.3004$ Ton -0.0236 Toff $0.0367 \mathrm{~V}$ [3.1]

\subsection{Analysis of variance [ANOVA]}

The analysis of variance for $\mathrm{S} / \mathrm{N}$ ratio and means are shown in table 5 and table 6 respectively. In an examination of variance table, the $\mathrm{P}$ value determines the most important process parameter. The parameter whose $\mathrm{P}$ value is less than 0.05 will be most effective factor. Current and pulse on time are significantly affect the 
material removal rate. From these tables it is concluded that Current is the most significant parameter for MRR followed by Pulse on Time. The main effect plot for $\mathrm{S} / \mathrm{N}$ ratio and means are shown in fig. 3 and 4 respectively.

Table.5: Analysis of Variance for S/N Ratio

\begin{tabular}{|l|l|l|l|l|l|l|}
\hline Sour & D & Seq & Adj & F & P & \% \\
\hline I & 3 & 7.348 & 2.449 & 416. & 0.00 & 52.90 \\
\hline Ton & 3 & 6.352 & 2.117 & 360. & 0.00 & 45.73 \\
\hline Toff & 3 & 0.054 & 0.018 & 3.11 & 0.18 & 0.39 \\
\hline V & 3 & 0.118 & 0.039 & 6.73 & 0.07 & 0.85 \\
\hline Error & 3 & 0.017 & 0.005 & & & \\
\hline Total & 15 & 13.89 & & & & \\
\hline
\end{tabular}

Table.6: Analysis of Variance for Means

\begin{tabular}{|l|l|l|l|l|l|l|}
\hline Sour & D & Seq & Adj & F & P & \% \\
\hline I & 3 & 57.81 & 19.27 & 752. & 0.00 & 54.30 \\
\hline Ton & 3 & 47.14 & 15.71 & 613. & 0.00 & 44.28 \\
\hline Toff & 3 & 0.499 & 0.166 & 6.50 & 0.07 & 0.47 \\
\hline V & 3 & 0.934 & 0.311 & 12.1 & 0.03 & 0.88 \\
\hline Error & 3 & 0.077 & 0.025 & & & \\
\hline Total & 15 & 106.4 & & & & \\
\hline
\end{tabular}

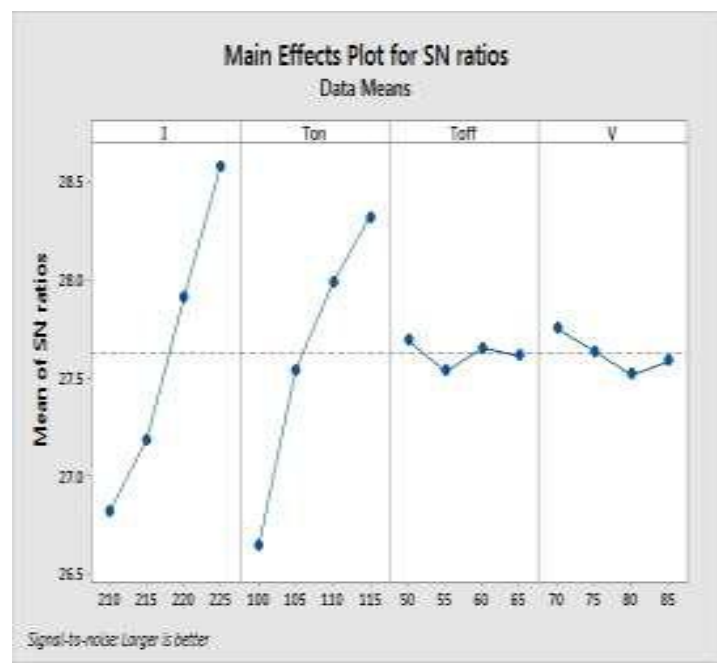

Fig.3: Main Effects Plot for S/N Ratio

From these graphs it is clears that as the current and pulse on time increases, the material removal rate also increases. As we increase the current and Pulse on time is show better value of MRR. These changes occur due to the fact that at the starting of electric discharge, the diameter of plasma channel is small, and lightweight electrons move towards the surface of work piece [positive pole] under the influence of electric field and cause the melting and evaporation of work piece material. As time going on, the diameter of plasma channel increases and more electrons move towards the anode and

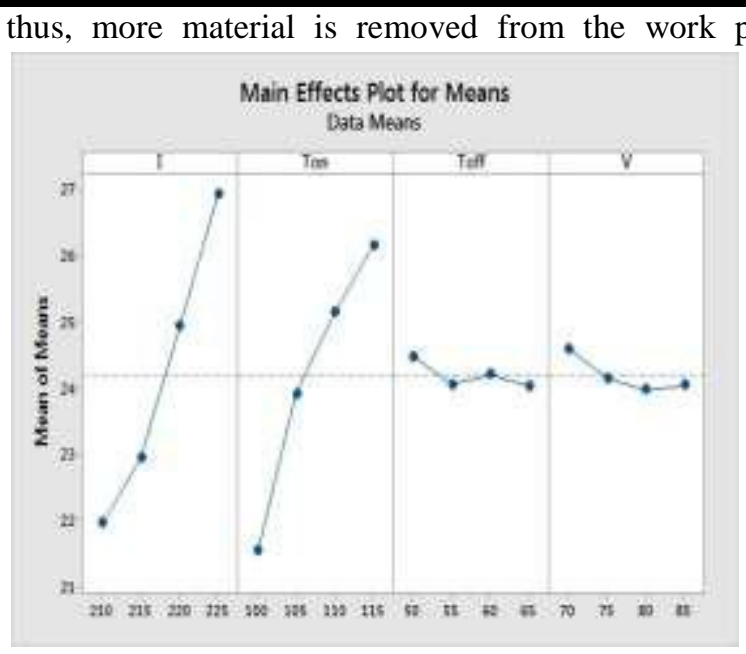

Fig.4: Main Effects Plot for Means

\section{CONCLUSIONS}

The main aim of this study was to find optimum values of process parameters for the maximum values of material removal rate by using Current, Pulse on Time, Pulse off Time and voltage as the process parameters. From this study, the following conclusions are drawn:

1. The material removal rate increases with the increase in current and Pulse on Time. As we increase the Current, the discharge energy also increase and the number of discharges within a period of time becomes more which results to more material removal rate.

2. As the voltage and pulse off time increases, the material removal rate decreases.

3. The pulse off time and voltage has no significant effect on material removal rate.

4. The material removal rate is maximum at fourth level of Current [225 Amp], Pulse on Time [115 $\mu \mathrm{s}]$ and first level of pulse off time and voltage i.e. and $50 \mu \mathrm{s}$ and $70 \mathrm{~V}$ respectively.

\section{REFERENCES}

[1] Ratilal P.Y, Patel N.K, Banker K.S, "Review of Research Work In Wire Cut Electro Discharge Machining on Metal Matrix Composite Materials”. International General for Technological Research in Engineering, P.P 1351-1354, 2016

[2] James D. A., Dr. Boopathi S., "Experimental study of Eco Friendly WEDM Process". International Journal of Innovative Research in Science, Engineering and Technology, PP. 666-675, 2016.

[3] Singh B., Misra J.P., "Study of Effect of Wire Related Parameters of Wire Cut EDM on Nimonic $263^{\prime \prime}$. IV $^{\text {th }}$ International Conference on Production and Industrial Engineering, PP. 1-10, 2016.

[4] Arikatla S.P., Dr. Mannan K.T., Dr. Krishnaiah A., "Optimization of Wire-Cut EDM of Process 
Parameters on Kerf Width in Machining of Titanium Alloy Using Response Surface Methodology". International Journal of Engineering Innovative \& Research, PP. 122-127, 2016.

[5] Atif M., Dr. Aggarwal G., Khan A., Ashar M., "Optimization of WIRE-CUT EDM Process Parameters". International Journal of Engineering Research, PP. 50-53, 2016.

[6] Gajjar D.H., Desai J.V., "Optimization of MRR,Surface Roughness and Kerf Width in Wire EDM Using Molybdenum Wire". International Journal for Research in Education, PP. 09 - 17, 2015.

[7] Sivaraman B., Eswaramoorthy C., Shanmugham E.P., "Optimal Control Parameters of Machining in CNC Wire Cut EDM". International Journal of Applied Science and Engineering Research, PP. 102121, 2015.

[8] Nagaraja R., Chandrasekaran K., Shenbhgaraj S., "Optimization of Parameter for Metal Matrix Composite in Wire EDM". International Journal of Engineering Science and Research Technology, PP. 570-574, 2015.

[9] Dabade U.A., Karidkar S.S., “Analysis of Response Variables in Wire-Cut EDM of Inconel 718 Using Taguchi Technique”. CIRP Conference on Manufacturing System, pp. 840-846, 2015.

[10] Goswami A., Kumar J., "Optimization of Wire Cut EDM of Nimonic $80 A$ using Taguchi's Approach and Utility Concept". International Journal of Engineering Science and Technology, PP. 236-246, 2014.

[11] Saini P.K., Verma M., "Experimental Investigation of Wire-EDM Process Parameters on MRR of Ti-6al$4 v$ Alloy". International Journal of Innovative Technology and Exploring Engineering, PP. 677692, 2014.

[12] Hemalatha K., Venkatachalapathy V.S.K., Alagumurthy N., "Surface Integrity analysis in Wire-Cut Electric Discharge Machining of Al 6063/Al2O3 Metal Matrix Composite through Response Surface Methodology". International Journal of Scientific \& Engineering Research, PP. 104-110, 2014.

[13] Ramesh S., Natarajan N., Krishnaraj V., "Experimental Investigation of Al6061/SiCp/B4Cp hybrid MMCs in Wire Electric Discharge Machine”. Indian Journal of Engineering and Materials Science, PP. 409-417, 2014.

[14] Lodhi B.K., Agarwal S., "Optimization of machining parameters in WEDM of AISI D3 Steel using Taguchi Technique" CIRP International Conference on High Performance Cutting, PP. 194199, 2014.
[15] Patel A.M., Patel S.P., "Parametric Optimization of Wire Cut Edm Machine on Hard Steel Alloy With Multiple Quality Characteristics". International Journal of Advanced Engineering Technology, PP. 74-77, 2013.

[16] Garg S.K., Manna A., Jain A., "Multi-Objective Optimization of Machining Characteristics during Wire Electrical Discharge Machining of $\mathrm{Al} / \mathrm{ZrO} \mathrm{O}_{2}$ Particulate Reinforced Metal Matrix Composite". Journal of Engineering Research, PP. 145-160, 2013.

[17] Durairaj M., Sudharsan D., Swaminathan N., "Analysis of Process Parameters in Wire EDM with Stainless Steel Using Single Objective Taguchi's Method and Multiobjective Gray Relational Grade". International Conference on Design And Manufacturing, PP. 868-877, 2013.

[18] Prakash J.U., Moorthy T.V., Peter J.M., "Experimental Investigation on Machinability of Aluminium Alloy [A413]/ Flyash/B4C Hybrids Composits Using Wire EDM". International Conference on Design and Manufacturing, PP. 13441353, 2013.

[19] Mevada J.R, Shah C.D, Khatri B.C, “A Wear Investigation of Repeatedly Used Wire in Wire Cut Electric Discharge Machine”. International Journal of Emerging Technology and Advanced Engineering, PP. 271-274, 2012.

[20]Kumar K., Agarwal S., "Multi-Objective Parametric Optimization on Machining With Wire Electric Discharge Machining”, International Journal of Advanced Engineering Sciences and Technologies, PP. 617-633, 2012.

[21] Sivakiran S., Reddy C.B., Eswara reddy C., "Effect Of Process Parameters On Mrr In Wire Electrical Discharge Machining Of En31 Steel". International Journal of Engineering Research and Applications, PP. 1221-1226, 2012.

[22] Shandilya P., "Parametric Optimization during Wire Electrical Discharge Machining using Response Surface Methodology”. Procedia Engineering, PP. 2371 - 2377, 2012.

[23] Rao P.S., Ramji K., Satyanarayana B., “ Effect of WEDM Conditions on Surface Roughness: a Prapmetric Optimisation using Taguchi Method". International journal of advanced engineering sciences and technologies. PP. 578-587, 2011.

[24] Antar M.T., Soo S.L, Aspinwall D.K., Jones D., Perej R., "Investigation of Wire Electrical Discharge Machining Characteristics of Al6063/SiCp Composites". International journal of advanced engineering sciences and technologies, PP. 975-986, 2011. 
[25] Shah A., Mufti N.A., Rakwal D., Bamberg E., "Effects of Varying Seven Different Machining Parameters In Addition to Varying the Material Thickness on the Machining Responses Such As Material Removal Rate, Kerf, and Surface Roughness of Tungsten Carbide". Journal of Materials Processing Technology, PP. 429-435 2009.

[26] Rao K.M., Satyanarayana S. and Parveen S., "Influence of Machining Parameters on Electric Discharge Machining of Maraging Steel". World Congress on Engineering, Vol. 2, PP. 1266-1278, 2008.

[27] Ramakrishnan R., Karunamoorthy L., "Modeling and Multi-Response Optimization of Inconel 718 on Machining of CNC WEDM Process". Journal of Materials Processing Technology, PP. 343-349, 2008. 